\title{
PERFORMANCE OF ACTIVATED SURFACE AREA OF COMBINED MACRO AND MICRO FIBERS IN CONCRETE
}

\author{
Mahmoud Abo El-Wafa Ahmed \\ Lecturer, Civil Engineering Department, Faculty of Engineering, \\ South Valley University, Aswan, Egypt.
}

(Received October 2, 2006 Accepted November 1, 2006)

\begin{abstract}
This research is oriented towards concrete reinforced with combinations of macro and micro polypropylene fibers with total volume fractions of about 1.0 percent, so it is most important to understand how the combinations of macro and micro polypropylene fibers behave in the cement composite matrix. Two groups of composite concrete were constructed using combinations of macro and micro polypropylene fibers. The experimental test results show a new interesting parameter to consider - the activated fiber surface area, which appears to be a good indicator of fiber performance. The combinations of macro and micro polypropylene fibers allowed a higher activated surface area of fibers that improve the composite concrete properties which are advantageous in achieving a high ultimate composite strength when compared to its individual fiber.
\end{abstract}

KEYWORDS: activated surface area of fibers, combined macro and micro polypropylene fibers, composite concrete properties.

\section{INTRODUCTION}

\subsection{Background Of Fiber Reinforced Concrete}

The use of fibers to reinforce a brittle material can be traced back to Ancient Egyptians times when straws or horsehair were added to mud bricks. Straw mats serving as reinforcements were also used at that time. Several different types of fibers, both manmade and natural, have been incorporated into concrete. Use of natural fibers in concrete precedes the advent of conventional reinforced concrete in historical context. However, the technical aspects of fiber reinforced concrete systems remained essentially undeveloped. Since the advent of fiber reinforced concrete in the 1940's a great deal of testing has been conducted on the various fibrous materials to determine the actual characteristics and advantages for each product. Several different types of fibers have been used to reinforce the cement-based matrices. Currently the commercial products are reinforced with steel, glass, polyester and polypropylene fibers. The selection of the type of fibers is guided by the properties of the fibers such as diameter, specific gravity, young's modulus, tensile strength etc and the extent these fibers affect the properties of the cement matrix [1-3]. 


\subsection{Behavior of Polypropylene Fibers in a Cement Matrix}

Until now, most fiber composite materials applications have employed macro fibers - fibers that average 0.5 to $1.0 \mathrm{~mm}$ in diameter and 25 to $60 \mathrm{~mm}$ in length. More recently micro polypropylene fibers, that are less than $0.1 \mathrm{~mm}$ in diameter and less than $15 \mathrm{~mm}$ long, used in traditional composite materials have been introduced into the concrete mixture to increase its toughness, or ability to resist crack growth. In fiber reinforced concrete, thousands of small fibers are dispersed and distributed randomly in the concrete during mixing, and thus improve concrete properties in all directions. Fibers help to improve the post peak ductility performance, pre-crack tensile strength, fatigue strength, impact strength and eliminate temperature and shrinkage cracks $[4,5]$.

This research is oriented towards concrete reinforced with combinations of macro and micro polypropylene fibers with total volume fractions of about 1.0 percent, so it is most important to understand how the combinations of macro and micro polypropylene fibers behave in the cement composite matrix. Two groups of composite concrete were constructed using combinations of macro and micro polypropylene fibers with total volume fractions of about 1.0 percent.

\section{EXPERIMENTAL PROGRAM}

\subsection{Materials And Mix Proportions}

To attain a meaningful comparison of the behavior of concrete reinforced with combinations of macro and micro polypropylene fibers with total volume fractions of about 1.0 percent. The proportioning of the concrete mixtures for testing is summarized in Table 1. All concrete mixtures were prepared with ordinary portland cement with 3.15 specific gravity and $345 \mathrm{~m}^{2} / \mathrm{kg}$ surface area. The fine aggregate used in concrete was natural sand with 2.55 specific gravity and 2.6 fineness modulus. The coarse aggregate was crushed basalt with $20 \mathrm{~mm}$ maximum nominal size and 2.6 specific gravity. High-range water reducing admixture (superplasticizer) was used as $1.0 \%$ of the total cement to all mixtures to enhance workability and handling characteristics and to prevent placing or compaction problems. The concrete is affected as the addition of polypropylene fibers has a definite negative impact on the slump, workability and finishability of the concrete. An optimum quantity of superplasticizer while mixing helps to avoid the problem of reduction in workability. Ready mixed concrete containing polypropylene fibers can be placed using conventional methods. Also during the process of incorporating polypropylene fibers, more compaction must be done than for the plain concrete. Generally, polypropylene fibers, when mixed with concrete, respond well to conventional compaction techniques and fibers do not easily segregate from the mix.

Table 1: Mix proportions of concrete.

\begin{tabular}{|c|c|c|c|c|c|c|c|c|c|}
\hline \multirow{2}{*}{$\begin{array}{c}\text { Max. } \\
\text { size } \\
(\mathrm{mm})\end{array}$} & \multirow{2}{*}{$\begin{array}{c}\text { Air } \\
(\%)\end{array}$} & \multirow{2}{*}{$\begin{array}{c}\text { Slump } \\
(\mathrm{cm})\end{array}$} & \multirow{2}{*}{$\begin{array}{c}W / C \\
(\%)\end{array}$} & $\begin{array}{c}H R W R^{*} \\
/ C\end{array}$ & \multicolumn{5}{|c|}{ Weight per unit volume $\left(\mathrm{kg} / \mathrm{m}^{3}\right)$} \\
\cline { 5 - 9 } & & & & $\mathrm{C}$ & $\mathrm{W}$ & $\mathrm{S}$ & $\mathrm{G}$ & $H R W R^{*}$ \\
\hline 20 & 5.5 & 18.5 & 40 & 1.0 & 450 & 175.5 & 590 & 1180 & 4.5 \\
\hline
\end{tabular}

*HRWR: High-range water reducing admixture 
The reinforcing materials used in this investigation included macro and micro polypropylene fibers are shown in Photo 1. The typical properties of the macro and micro polypropylene fibers were given in Table 2 [1,2].

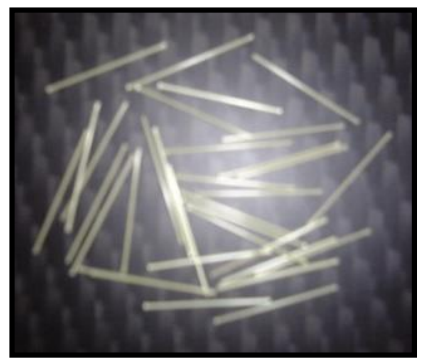

(a) 3200d-40mm (macro fibers)

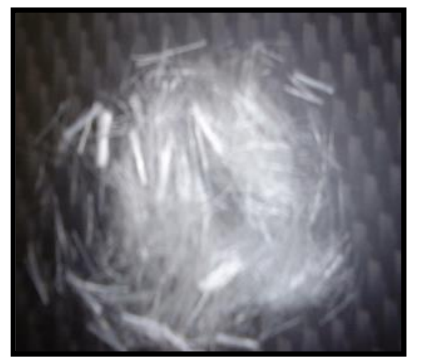

(b) $350 \mathrm{~d}-6 \mathrm{~mm}$ (macro fibers)

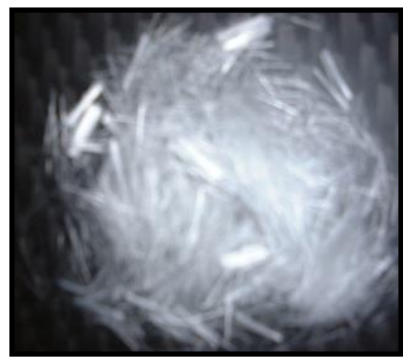

(c) $20 \mathrm{~d}-6 \mathrm{~mm}$ (micro fibers)

Photo 1: Macro and micro polypropylene fibers.

Table 2: Typical properties of macro and micro polypropylene fibers $[1,2]$.

\begin{tabular}{|c|c|c|c|c|c|c|c|}
\hline $\begin{array}{l}\text { Fiber's } \\
\text { type }\end{array}$ & $\begin{array}{c}\text { Diameter } \\
(\mathbf{m m})\end{array}$ & $\begin{array}{c}\text { Length } \\
(\mathrm{mm})\end{array}$ & $\begin{array}{c}\text { Surface } \\
\text { area } \\
\left(\mathbf{m m}^{2}\right)\end{array}$ & $\begin{array}{l}\text { Density } \\
\left(\mathrm{g} / \mathrm{cm}^{3}\right)\end{array}$ & $\begin{array}{c}\text { Tensile } \\
\text { strength } \\
\text { (MPa) }\end{array}$ & $\begin{array}{c}\text { Young's } \\
\text { modulus } \\
(\mathrm{GPa})\end{array}$ & $\begin{array}{c}\text { Elongation } \\
(\%)\end{array}$ \\
\hline $\begin{array}{c}\text { 3200d } \\
(\text { macro })\end{array}$ & 0.705 & 40 & 88.63 & \multirow{3}{*}{0.91} & \multirow{3}{*}{$500-750$} & \multirow{3}{*}{$5-10$} & \multirow{3}{*}{$8-10$} \\
\hline $\begin{array}{c}\text { 350d } \\
(\text { macro) }\end{array}$ & 0.233 & 6 & 4.39 & & & & \\
\hline $\begin{array}{c}\text { 20d } \\
\text { (micro) }\end{array}$ & 0.056 & 6 & 1.05 & & & & \\
\hline
\end{tabular}

\subsection{Testing Procedures}

The testing program included two groups of concrete mixtures shown in Table 3. The first group (I) was prepared from concrete mixtures reinforced with combining 3200d-40mm (macro) and 20d-6mm (micro) polypropylene fibers with total volume fractions of about 1.0 percent (M1-M5). The second group (II) was prepared from concrete mixtures reinforced with combining 350d-6mm (macro) and $20 \mathrm{~d}-6 \mathrm{~mm}$ (micro) polypropylene fibers with total volume fractions of about 1.0 percent (M6M10). Both groups were prepared from the same concrete mixtures.

A conventional rotary drum concrete mixer was used. The coarse aggregate, cement and sand were first mixed in dry state for about one minute. The water and high-range water reducing admixture (superplasticizer) were mixed together and added gradually to the dry mixture for about two minutes. Finally, the fibers were added slowly to the running mixer for another two minutes to achieve uniform distribution of the fibers. Workability of the fresh concrete was assessed using the slump test and air content test after mixing. After casting, the concrete specimens were compacted using a vibrating table. Cubes $(150 \mathrm{~mm})$ and cylinders $(\phi 150 \times 300 \mathrm{~mm})$ were prepared according to Egyptian Code of Practice (E.C.O.P.) for the compressive strength and 
splitting tensile strength testing, respectively, whereas prisms $(100 \times 100 \times 500 \mathrm{~mm})$ were made according to E.C.O.P. for the flexural strength testing.

Table 3: Concrete mixtures reinforced with combining macro and micro fibers

First group (I):

\begin{tabular}{|c|c|c|}
\hline \multirow{2}{*}{ Mixtures } & \multicolumn{2}{|c|}{ Total volume fraction $1.0 \%$} \\
\cline { 2 - 3 } & 3200d (macro) & 20d (micro) \\
\hline M1 & 1.0 & 0.0 \\
\hline M2 & 0.75 & 0.25 \\
\hline M3 & 0.5 & 0.5 \\
\hline M4 & 0.25 & 0.75 \\
\hline M5 & 0.0 & 1.0 \\
\hline
\end{tabular}

Second group (II):

\begin{tabular}{|c|c|c|}
\hline \multirow{2}{*}{ Mixtures } & \multicolumn{2}{|c|}{ Total volume fraction $1.0 \%$} \\
\cline { 2 - 3 } & 350d (macro) & 20d (micro) \\
\hline M6 & 1.0 & 0.0 \\
\hline M7 & 0.75 & 0.25 \\
\hline M8 & 0.5 & 0.5 \\
\hline M9 & 0.25 & 0.75 \\
\hline M10 & 0.0 & 1.0 \\
\hline
\end{tabular}

\section{RESULTS AND DISCUSSION}

\subsection{Activated Fiber Surface Area $\left(S_{a c t}\right)$}

The surface area of the fibers in a composite plays an important role in the performance of fiber reinforced concrete. As the number of fibers increase, the total surface area of the fibers increases in the composite. For the same volume percent of fibers in a composite, there will be more number of micro fibers (small diameter fibers) than macro fibers (large diameter fibers). Thus, for the same volume percent of fibers in a composite concrete reinforced with combining macro and micro fibers, the surface area of combining macro and micro fibers will be more than the individual fiber. Therefore, the total surface area $\left(S_{t o t}\right)$ of the combining macro and micro polypropylene fibers in a composite concrete per unit volume is directly proportional to the volume fraction percent of the fibers and the number of the fibers. The total surface area $\left(S_{t o t}\right)$ was calculated using the formula that is,

$$
S_{\text {tot }}=\left(N_{f} S_{\text {fib }}\right)_{\text {macro }}+\left(N_{f} S_{\text {fib }}\right)_{\text {micro }}
$$

where:

$$
\begin{aligned}
& N_{f}=\frac{V_{f}}{V_{f i b}} \quad \ldots .(2-\mathrm{a}) \quad \text { and } \quad S_{f i b}=\pi D_{f i b} L_{f i b} \quad \ldots \text { (2-b) } \\
& A_{f i b}=\frac{\pi D_{f i b}^{2}}{4} \ldots(3-\mathrm{a}) \quad \text { and } \quad V_{f i b}=A_{f i b} L_{f i b} \ldots(3-\mathrm{b})
\end{aligned}
$$

in which $S_{t o t}$ is the sum of the total surface area of combining macro and micro fibers in the composite, $N_{f}$ is the number of fibers in the composite, $V_{f}$ is the volume fraction percent of the fibers, $A_{f i b}$ is the cross sectional area of one fiber, $S_{f i b}$ is the surface area of one fiber, $V_{f i b}$ is the volume of one fiber, $D_{f i b}$ is the diameter of one fiber and $L_{f i b}$ is the length of one fiber. 
It is not reliable that the total numbers of fibers are getting bonded well to the composite concrete. By examination of the interface bond between fibers and composite concrete shown in Fig. 1, it is noticed that there are two types of interfacial bond of fiber composite concrete, either debonding at the interface of fiber or fiber breakage. The rest of fibers have a good bond condition to the composite concrete. Therefore, the repetitive analysis of experimental data shows that it is more reliable that about two thirds of the number of fibers can be more efficient and have a bonded well to the composite concrete. Hence, the author introduces the activated fiber surface area $\left(S_{a c t}\right)$ as a new parameter which appears to be a good indicator of fiber performance when a composite concrete reinforced with combined macro and micro polypropylene fibers, see Fig. 2. This is defined in formula (4),

$$
S_{a c t}=\left(N_{f}^{2 / 3} S_{\text {fib }}\right)_{\text {macro }}+\left(N_{f}^{2 / 3} S_{\text {fib }}\right)_{\text {micro }}
$$

in which $S_{a c t}$ is the activated fiber surface area of combined macro and micro fibers in the composite, $N_{f}^{2 / 3}$ is the number of fibers powered by two thirds and $S_{f i b}$ is the surface area of one fiber.

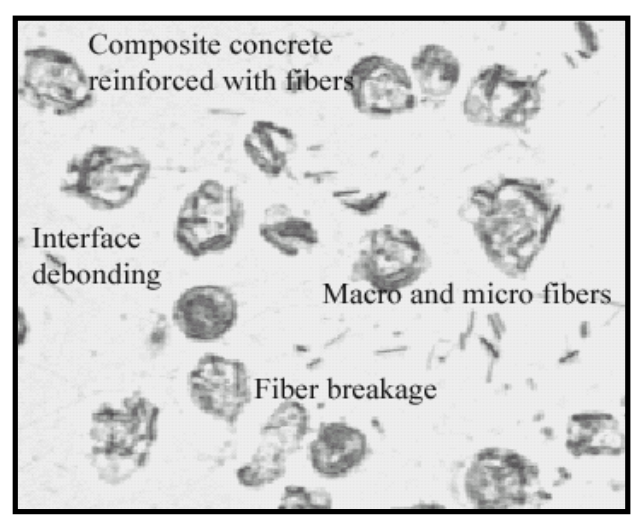

Fig. 1: Interfacial bond of fiber composite.

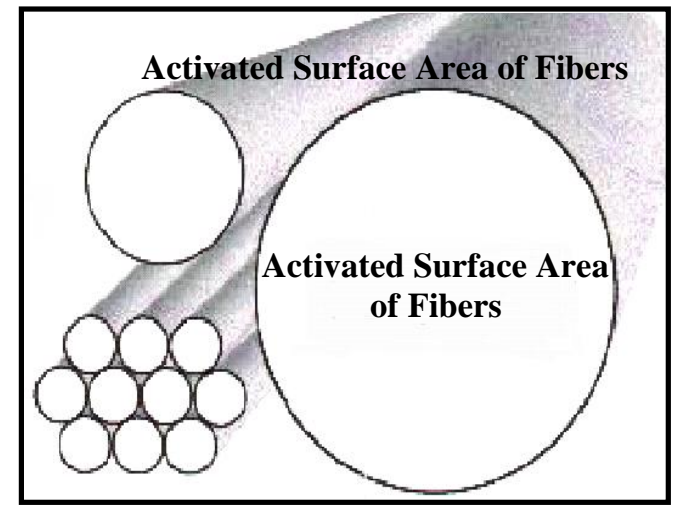

Fig. 2: Activated surface area of fibers.

The relationship between the activated fiber surface area $\left(S_{a c t}\right)$ and mixing ratio of combining macro and micro fibers, with total volume fractions of about 1.0 percent are shown in Figs. 3 and $\mathbf{4}$. Using the formula (4), it is found that the maximum value of activated fiber surface area of combined macro and micro fibers depends on the volume fraction percent, diameter and number of the fibers in the composite. The maximum value of activated surface area of combining $3200 \mathrm{~d}$ (macro) and $20 \mathrm{~d}$ (micro) fibers at fiber's ratio is $0.35: 0.65 \%$ by volume respectively, see Fig. 3 . While the maximum value of activated surface area of combining $350 \mathrm{~d}$ (macro) and $20 \mathrm{~d}$ (micro) fibers at fiber's ratio is $0.20: 0.80 \%$ by volume respectively, see Fig. 4. This means that the maximum value of activated fiber surface area should give more favorable composite properties that are advantageous in achieving a high ultimate composite strength. 

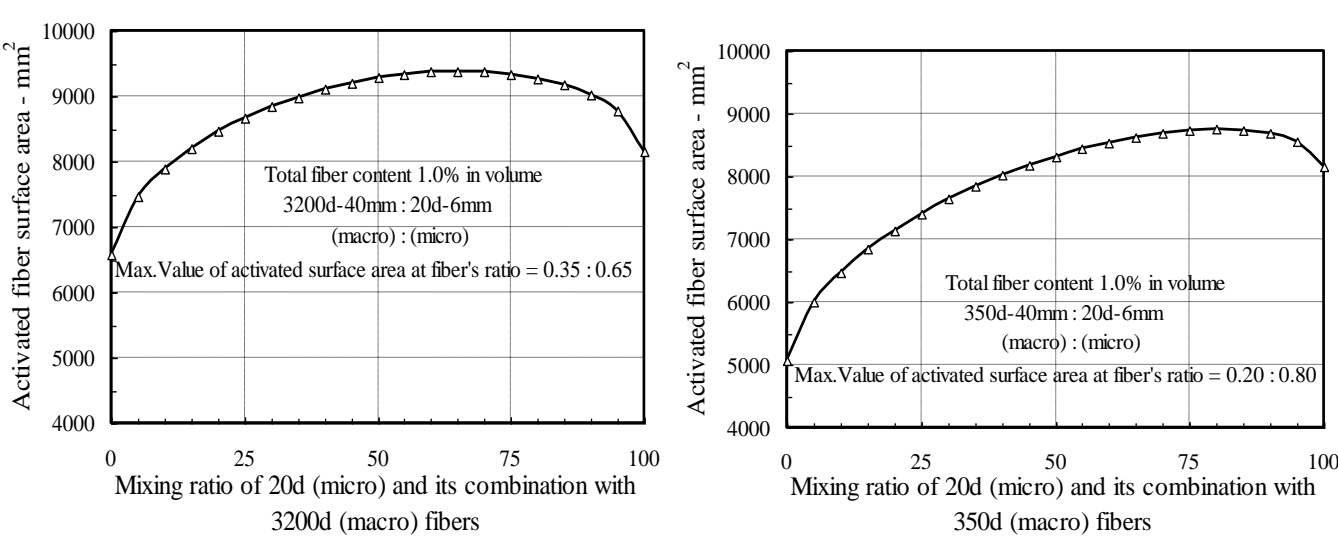

Fig. 3: Effect of combining 3200d (macro) and 20d (micro) fibers on the activated surface area.

Fig. 4: Effect of combining 350d (macro) and $20 \mathrm{~d}$ (micro) fibers on the activated surface area.

\subsection{Effect of $\left(S_{a c t}\right)$ of Fibers on Splitting Tensile Strength}

Splitting tensile tests were carried out to characterize the effect of activated fiber surface area $\left(S_{a c t}\right)$ on the tensile properties of the composite concrete reinforced with combining macro and micro polypropylene fibers with total volume fraction 1.0 percent after being cured for 7 and 28 days. The combinations of macro and micro polypropylene fibers allowed a higher activated surface area of fibers and more favorable composite strength when compared to its individual fiber. The higher value of activated fiber surface area enhances the higher values in splitting tensile strength of composite concrete, see Fig. 5, and this is a more reliable means as mentioned above.
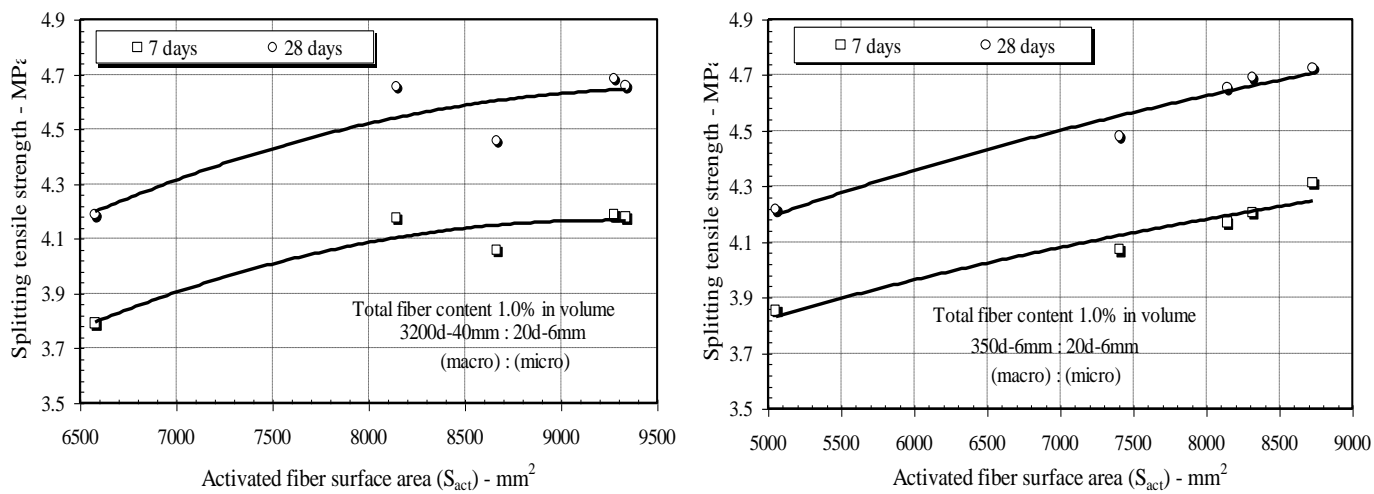

Fig. 5: Effect of activated fiber surface area $\left(S_{a c t}\right)$ on splitting tensile strength.

\subsection{Effect of $\left(S_{a c t}\right)$ of Fibers on Modulus of Rupture}

Flexural tests were carried out on four-point bending prisms to show the effect of activated fiber surface area $\left(S_{a c t}\right)$ on the modulus of rupture of the composite concrete reinforced with combining macro and micro polypropylene fibers with total volume fraction 1.0 percent after being cured for 7 and 28 days. It is demonstrated that the higher value of activated fiber surface area exhibits the higher modulus of rupture of composite concrete, see Fig. 6. Therefore, this means that the activated fiber surface area has played an important role in increasing the capacity of the composite concrete. 

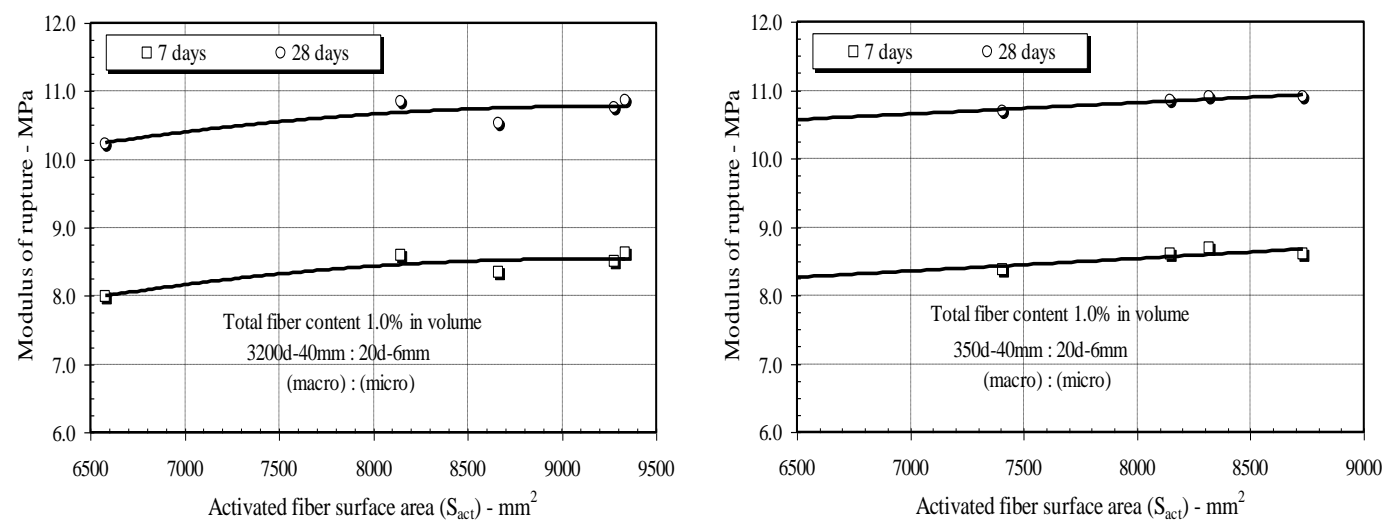

Fig. 6: Effect of activated fiber surface area $\left(S_{a c t}\right)$ on modulus of rupture.

\subsection{Effect of $\left(S_{a c t}\right)$ of Fibers on Compressive Strength}

Compressive strength was determined for the composite concrete reinforced with combining macro and micro polypropylene fibers with total volume fraction 1.0 percent after being cured for 28 days. It seems that the combining macro and micro polypropylene fibers has a relatively small favorable effect on the compressive strength compared to the tensile and flexural properties of the composite, see Fig. 7.

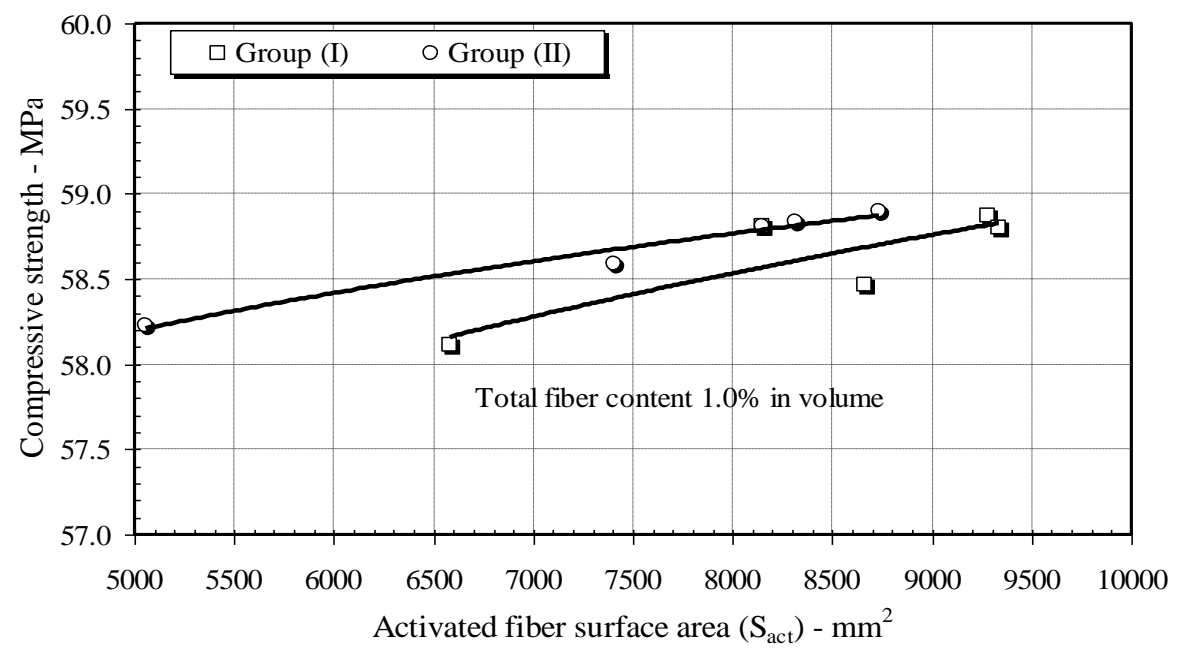

Fig. 7: Effect of activated fiber surface area $\left(S_{\text {act }}\right)$ on compressive strength.

\section{CONCLUSIONS}

The experimental test results show a new interesting parameter to consider the activated fiber surface area, which appears to be a good indicator of fiber performance. The combinations of macro and micro polypropylene fibers allowed a higher activated surface area of fibers that have more favorable composite concrete properties that are advantageous in achieving a high ultimate composite strength when compared to its individual fiber. The composite concrete reinforced with combining 
macro and micro polypropylene fibers has simultaneously contributed to the composite. The combining macro and micro polypropylene fibers has a relatively small favorable effect on the compressive strength compared to the tensile and flexural properties of the composite. Supplementary investigations are recommended to promote the effect of activated surface area of combined macro and micro polypropylene fibers in concrete.

\section{REFERENCES}

[1] Ramakrishnan, V.: "Concrete Fiber Composite for The Twenty First Century", Real World Concrete, Proceedings of R. N. Swamy Symposium at $5^{\text {th }}$ CANMET/ACI International Conference, Edited by Singh, G., USA, pp. 111-143, (1995).

[2] Bayasi, Z., and Zeng, J.: "Properties of Polypropylene Fiber Reinforced Concrete", ACI Materials Journal, Vol. 90, No. 6, pp. 605-610, (1993).

[3] Mindess, S., and Banthia, N.: "Fiber Reinforced Cementitious Composites: Current Practice and Future Prospects, Proceedings of V. M. Malhotra, Edited by Mehta, P. K., ACI, SP-144, pp. 417-446, (1994).

[4] Banthia, N., and Soleimani, S.: "Flexural Response of Hybrid Fiber-Reinforced Cementitious Composites", ACI Materials Journal, Vol. 102, No. 6, pp. 382-389, (2005).

[5] Roesler, J., Salah, A., David. A., Klaus-Alexander, R., and Gregory, R.: "Effect of Synthetic Fibers on Structural Behavior of Concrete Slabs-on-Ground," ACI Materials Journal, Vol. 103, No. 1, pp. 3-10, (2006).

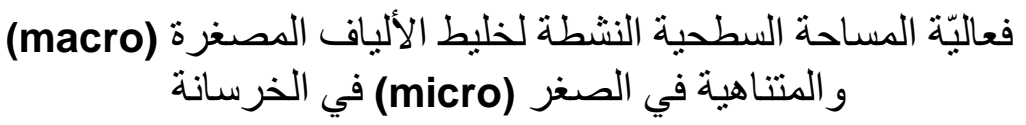

في الخرسانة المسلحة بالألياف، عادةً ما يكون توزيع و أنتشار الألياف عشو ائياً في خليط الخرسانة

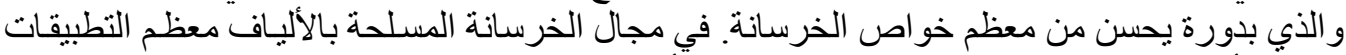

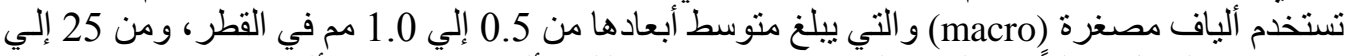

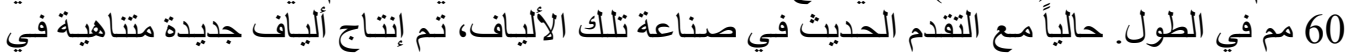

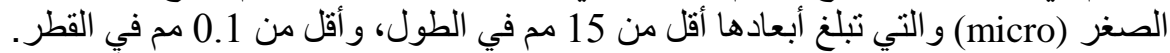

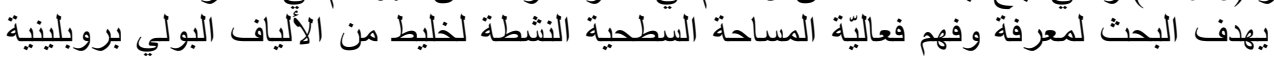

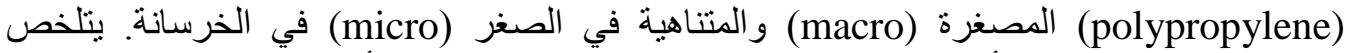
البرنامج العملي للبحث في أعداد مجمو عتين من خليط الخرسانة المسلحة بالألياف، وكل فئل مجمو عة تحتوي علي خليط من الألياف المصغرة (macro) و المتناهية في الصغر (micro) بنسبة حو الي 1.0 \%

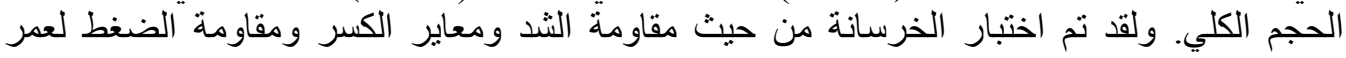

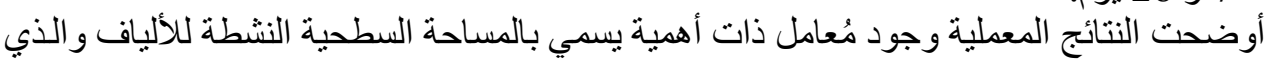

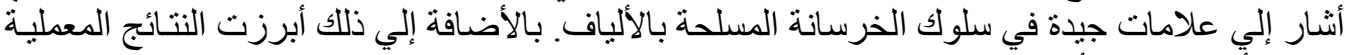

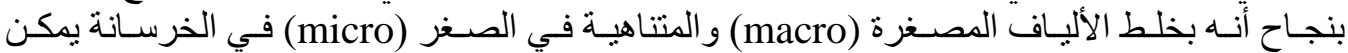

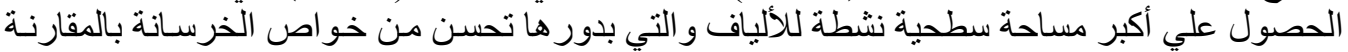
بعمل خليط الخرسانة من نوع و احير مد من تللك الألياف. 